\title{
A Case of Acute Lymphoblastic Leukemia Presenting as Unilateral Sternoclavicular Joint Arthritis and Mass
}

\author{
Eun-Jung Park, M.D. ${ }^{1}$, Chang Lim Hyun, M.D., Ph.D. ${ }^{2}$, Jinseok Kim, M.D., Ph.D. ${ }^{3}$ \\ ${ }^{1}$ Division of Rheumatology, Department of Internal Medicine, National Medical Center, Seoul, ${ }^{2}$ Department of Pathology and ${ }^{3}$ Division of \\ Rheumatology, Department of Internal Medicine, Jeju National University School of Medicine, Jeju, Korea
}

\begin{abstract}
We report a patient with acute lymphoblastic leukemia of bone and joint, which is very rare, presenting as monoarthritis [1-4]. A 57-year-old woman presented with the complaints of right sternoclavicular (SC) joint area pain with swelling, malaise, and intermittent fever lasting for two weeks. She had no past medical history and denied trauma or injection of affected joint. The patient had episodes of fever up to $39.2^{\circ} \mathrm{C}$, and mild tachycardia. On physical examination, localized heat in the right $\mathrm{SC}$ joint and a $2 \times 3 \mathrm{~cm}$ soft and tender mass around the joint were detected. Laboratory results showed hemoglobin 10.6 $\mathrm{g} / \mathrm{dL}$, hematocrit $30.3 \%$, platelets $242,000 / \mathrm{mm}^{3}$, and white blood cell count $5,400 / \mathrm{mm}^{3}$ including absolute neutrophil count $870 / \mu \mathrm{L}$, segment neutrophil $39.6 \%$, and monocyte $18.9 \%$. Erythrocyte sedimentation rate was $28 \mathrm{~mm} /$ hour and C-reactive protein was $6.34 \mathrm{mg} / \mathrm{dL}$.
\end{abstract}

Otherwise, blood laboratory findings and urinalysis were unremarkable. Plain radiography of clavicle and sternum showed no abnormal finding. Magnetic resonance imaging demonstrated focal cortical disruption at anteromedial aspect of right distal clavicle, decreased bone marrow signal intensity on $\mathrm{T} 1$ image, and right SC joint arthritis, which suggested septic arthritis with osteomyelitis or malignancy (Figure 1A $\sim \mathrm{C}$, arrows). Bone biopsy of right distal clavicle revealed increased atypical cell infiltration with necrosis, which was consistent with leukemic infiltration (Figure 2A; H\&E stain, $\times 400$, arrows). The bone marrow biopsy showed nearly packed marrow with myelofibrosis (Figure 2B; H\&E stain, $\times 400$, arrowheads). On aspirate smears, blasts were present in up to $87.8 \%$ of all marrow nucleated cells. They were small to large-sized with round nuclei, dispersed chromatin and
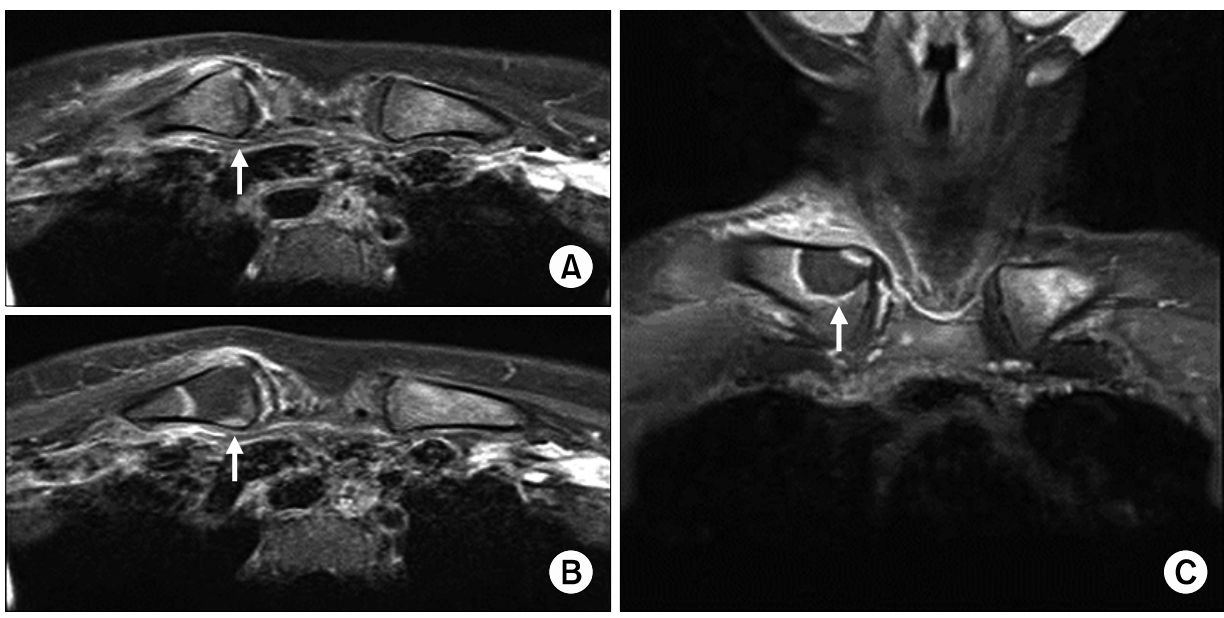

Figure 1. Magnetic resonance imaging demonstrated focal cortical disruption at anterior mid aspect of right distal clavicle and decreased bone marrow signal intensity on $\mathrm{T} 1$ image, and right sternoclavicular joint arthritis, which suggested septic arthritis with osteomyelitis or malignancy $(\mathrm{A} \sim \mathrm{C}$, arrows).

Received : October 22, 2019, Revised : December 2, 2019, Accepted : December 3, 2019

Corresponding to : Jinseok Kim (1D)http://orcid.org/0000-0001-7518-3284

Division of Rheumatology, Department of Internal Medicine, Jeju National University School of Medicine, 15 Aran 13-gil, Jeju 63241, Korea. E-mail : slera@yahoo.com

Copyright (c) 2020 by The Korean College of Rheumatology. All rights reserved.

This is an Open Access article, which permits unrestricted non-commerical use, distribution, and reproduction in any medium, provided the original work is properly cited. 

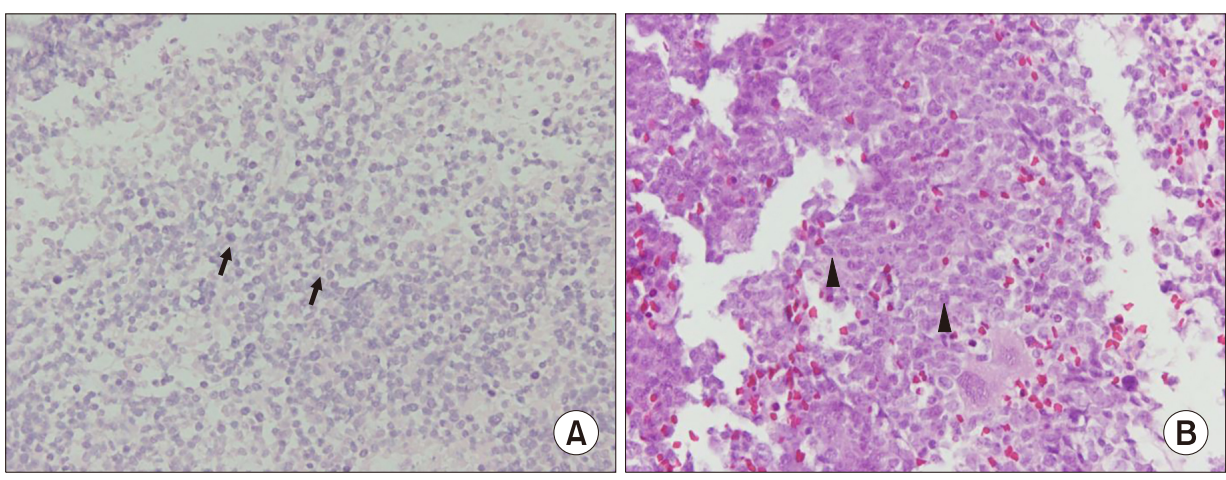

Figure 2. Bone biopsy of right distal clavicle revealed increased atypical cell infiltration with necrosis, which was consistent with leukemic infiltration $(A$, H\&E stain, $\times 400$, arrows). The bone marrow biopsy showed nearly packed marrow with myelofibrosis (B, H\&E stain, $\times 400$, arrowheads). inconspicuous nucleoli. Normal erythroid and myeloid elements were markedly suppressed. Cytochemical stain on aspiration and biopsy demonstrated negative MPO and PAS and positive CD 34 and CD 20. All findings suggested B-lymphoblastic leukemia with chloroma of right distal clavicle and SC joint. This case indicates that malignancy should also be considered in evaluation of monoarthritis, and that chloroma of bone can precede the onset of acute lymphoblastic leukemia.

\section{ACKNOWLEDGMENTS}

This work has supported by the 2019 education, research and student guidance grant funded by Jeju National University.

\section{CONFLICT OF INTEREST}

No potential conflict of interest relevant to this article was reported.

\section{AUTHOR CONTRIBUTIONS}

Among the authors, E.J.P. appointed topic, wrote and revised the manuscript. C.L.H. was responsible for the analysis and the interpretation of the pathology. J.S.K. determined and adjusted the topic, concept and drafting of the manuscript.

\section{REFERENCES}

1. Kubota H, Saida S, Kouzuki K, Hamabata T, Daifu T, Kato I, et al. [Pediatric acute lymphoblastic leukemia presenting with bone and joint pain]. Rinsho Ketsueki 2018;59: 167-73. Japanese.

2. Pécheux L, Forget P, Geurten C, Rausin L, Nicolescu R, Hoyoux C. [Bone disorders and complications of pediatric acute lymphoblastic leukemia : monocentric study and review of the literature]. Rev Med Liege 2018;73:575-82. French.

3. Rehman A, Abbas N, Saba T, Rahman SIU, Mehmood Z, Kolivand $\mathrm{H}$. Classification of acute lymphoblastic leukemia using deep learning. Microsc Res Tech 2018;81:1310-17.

4. Tragiannidis A, Vasileiou E, Papageorgiou M, Damianidou L, Hatzipantelis E, Gombakis N, et al. Bone involvement at diagnosis as a predictive factor in children with acute lymphoblastic leukemia. Hippokratia 2016;20:227-30. 